\title{
O PAPEL DO DOCENTE UNIVERSITÁRIO NA EDUCAÇÃO A DISTÂNCIA
}

\author{
Simone Gonçalves Franzati ${ }^{1}$
}

RESUMO: Esse artigo aqui presente propõe apresentar à relevância do papel do docente universitário na educação a distância, sendo que, a educação desde seus primórdios vem se transformando e chegou para romper barreiras, o docente atualmente, não é mais a única fonte do conhecimento, mas aquele que estimula e orienta na busca de novos conhecimentos.

Palavras-chave: Educação a Distância, O papel e as funções do Professor Universitário na Educação a Distância, Educação a Distância no Ensino Superior.

ABSTRACT: This article proposes to present the relevance of University teacher's the role in relation to the distance education, since Education has been changing and break barriers down. Teachers, nowadays, is no longer the only source of knowledge but the person who encourages and guides the students for knowledge achievement.

Key-words: Distance Education, The role and functions of University Professor in Distance Education, Distance Education in Higher Education.

\section{INTRODUÇÃO}

A educação desde seus primórdios vem se modificando e o mundo tradicionalmente tem sempre incorporado sistemas de atualização e especialização para os docentes em exercício, sendo assim de grande importância na vida de todos nós.

\footnotetext{
${ }^{1}$ Mestranda em Educação, Arte e História da Cultura - Universidade Presbiteriana Mackenzie. Simone.franzati@gmail.com / simonefranzati@hotmail.com. Licenciatura Plena em Pedagogia - Faculdades Integradas Campos Salles. Especialista em Formação de Docentes para o Ensino Superior - Universidade Nove de Julho
} 
A educação pós-moderna chega para romper barreiras, dar mais autonomia aos docentes, principalmente aos discentes que podem "estudar" e aprender de qualquer lugar, no tempo que dispor e explorando diversas formas de construção e produção de conhecimentos. Podemos encontrar em Belloni (2001), estas e outras considerações a respeito da Educação $(\mathrm{EaD})$.

Devido à relevância que a $\mathrm{EaD}$ vem assumindo no cenário nacional e internacional, bem como em suas manifestações políticas, pedagógicas e didáticas, cabe ressaltar alguns marcos de sua trajetória. Sabemos que a $\mathrm{EaD}$ não é nova, o que tem mudado primordialmente são as tecnologias que são utilizadas em diferentes projetos e cursos de EaD. Esta modalidade de educação surgiu no final do século XIX, onde instituições particulares nos EUA e na Europa ofereciam cursos por correspondência destinados ao ensino de temas vinculados a ofícios de escasso valor acadêmico.

Muitos não acreditavam no seu potencial, pois parecia que era um estudo para os que fracassaram na vida escolar convencional. Somente na década de 60 , com a criação de universidades à distância que competiam com a modalidade presencial, foi possível superar muitos preconceitos da EaD (LITWIN, 2001: 15). Mas, então, o que vem a ser esta nova modalidade de ensino? É um ensino que pode utilizar como veículo para comunicação as últimas conquistas da tecnologia (LITWIN, 2001). Mesmo que o aluno esteja em lugares mais distantes recebem livros, CD's, vídeos ou transmissões por intermédio da televisão. E a comunicação com seus professores acontecem em bibliotecas, colégios, em casa, no trabalho, com livros, papéis ou computadores. Desta forma o ensino a distância fica caracterizado por sua flexibilidade em torno da proposta de ensino - aprendizagem diante do grande avanço tecnológico, possibilitando uma interação entre professores e alunos, encurtando as distâncias.

De acordo com Litwin (2001), as propostas de EaD estão se caracterizando pela multiplicidade de recursos pedagógicos objetivando facilitar a construção do conhecimento. Atualmente estamos diante de uma geração de jovens totalmente voltados para a tecnologia, às empresas cada vez mais otimizando seus treinamentos de capacitação através de e-learnings. E a área da educação, não pode assistir a essa transformação passivamente é preciso acompanhar o mercado, considerando que a EaD 
está centrada no processo de aprendizagem do aluno e não no processo de ensino do professor.

O professor passa a exercer uma função de prestador de serviços para este aluno onde o ensina a aprender e forma o aprendente autônomo. $\mathrm{Na} \mathrm{EaD}$ a maior parte do tempo do professor não é "lecionar", mas acompanhar, gerenciar, supervisionar, avaliar o que está acontecendo ao longo do curso. O papel do professor muda claramente: orienta, mais do que explica. Isto também pode acontecer na educação presencial; mas até agora desenvolvemos a cultura da centralidade do papel do professor como o falante, o que informa, aquele que proporciona as respostas. A EaD de qualidade nos mostra algumas formas de focar mais a aprendizagem do que o ensino (MORAN, 2007). Sabemos que ainda é muito cedo para percebermos a autonomia, a independência do novo perfil do estudante universitário e sabemos que isso ainda não ocorre nas universidades.

O que pretendo ao levantar essa discussão, é perceber que o ensino superior precisa sofrer transformações de modo que incentive, estimule e encoraje o aluno a uma aprendizagem autônoma.

“As sociedades contemporâneas e as do futuro próximo, nas quais vão atuar as gerações que agora entram na escola, requerem um novo tipo de indivíduo e de trabalhador em todos os setores econômicos: a ênfase estará na necessidade de competências múltiplas do indivíduo, no trabalho em equipe, na capacidade de aprender e de adaptar-se a situações novas. Para sobreviver na sociedade e integra-se ao mercado de trabalho do século XXI, o indivíduo precisa desenvolver uma série de capacidades novas: autogestão (capacidade de organizar seu próprio trabalho), resolução de problemas, adaptabilidade e flexibilidade diante de novas tarefas, assumirem responsabilidades e aprender por si próprio e constantemente trabalhar em grupo de modo cooperativo e pouco hierarquizado" (BELLONI, 2003: 26). 
Entendemos que a $\mathrm{EaD}$ pode contribuir na formação do perfil do novo profissional que o mercado exige, uma vez que estimula a educação como um processo de auto-aprendizagem, no estudante autônomo capaz de coordenar seu próprio processo de aprendizagem. Como o professor universitário está se preparando para essa nova tendência? Sendo assim, esse presente artigo visa aprofundar-se cientificamente no comportamento e analisar as possíveis dificuldades do professor universitário diante deste novo método de ensino.

Abaixo seguem os objetivos específicos desta análise:

- A separação entre professor e aprendente e a produção de materiais "préempacotados" deslocam o enfoque da tomada de decisões sobre o currículo do aprendente para a instituição e seu staff;

- Os pacotes pré-parados de materiais de curso exercem uma autoridade indevida para muitos estudantes, que se tornam consequentemente menos aptos a questionar o que aprendem;

- Os cursos tendem a ser demasiado pesado em termos de conteúdo ${ }^{2}$, o que pode encorajar os estudantes a enforcarem a "digestão" dos conteúdos em detrimento da busca do significado e da aplicação dos conhecimentos;

- Os cursos em geral fornecem os materiais de referência prescritos, o que é lógico e útil para estudantes isolados em casa (e de fontes de informação), mas isto não os encoraja a buscar suas próprias fontes ou desenvolver "competência de biblioteca";

- Pacotes de cursos, produzidos centralizadamente, têm dificuldade de incluir a infinita variedade de tipos de tutoria e serviços de apoio demandados pelos aprendentes e oferecem pouco para suas diferenças individuais de background, necessidades e estilos de aprendizagem;

- Embora a maioria das universidades abertas ofereça acesso a serviços de tutoria e mesmo atividades presenciais de apoio, faltam aos estudantes um retorno imediato vindo de uma interação mais regular com outros estudantes e com os tutores, o

\footnotetext{
${ }^{2}$ Por que esta é a característica de maior visibilidade entre os pares da academia e para os estudantes.
} 
que os torna menos apto a reflexão, à discussão ou questionamento com relação aos conteúdos da aprendizagem (PAUL, 1990: 33).

É possível que se confirme na EaD a dificuldade do uso das (NTIC) ${ }^{3}$. O professor agora precisa integrar a pedagogia e a técnica para mediatizar os cursos: "Isto posto, saber "mediatizar" será uma das competências mais importantes e indispensáveis à concepção e realização de qualquer EaD. De certa forma, ao preparar suas aulas e os materiais que iram utilizar, o professor "mediatiza", embora o meio mais importante neste caso seja a linguagem verbal direta, o que significa que mediatizar o ensino não é uma competência totalmente nova. O que é novo é o grande elenco de mídias cada vez mais "performantes" disponíveis hoje no mercado e já sendo utilizadas por muitos aprendentes fora da escola, o que acarreta uma crescente exigência de qualidade técnica por parte dos estudantes" (BELLONI, 2003).

Considerando que vivemos numa sociedade onde cada vez mais a tecnologia invade os ambientes de trabalho, se expandindo para as esferas da vida social, concluímos que se a educação não incorporar as NTIC em seu dia a dia, a comunicação com essa nova geração será seriamente prejudicada, pois os jovens perderão a motivação e se afastarão de instituições obsoletas. Isso não quer dizer que as NTIC vão substituir os livros didáticos, mas serão instrumentos imprescindíveis neste intercâmbio. O que nos leva ao problema fundamental da educação, a formação de professores, pois não se pode pensar em qualquer inovação educacional sem duas condições prévias: a produção de conhecimento pedagógico e a formação de educadores.

A perspectiva da formação de professores exige a reflexão sobre como integrar as TICs à educação como caminho, enquanto futuros usuários ativos e críticos bem como os professores conceptores de materiais para a aprendizagem aberta e a distância (BELLONI, 2003). Usar intensamente a tecnologia no ensino torna o mais complexo, consequentemente vem à transformação do papel do docente no ensino universitário a distância: a preparação e autoria de cursos agora serão apresentadas em livro-texto ou manual, programas em áudio, vídeo ou informática. A orientação será através de tutoria à distância, individualizada, mediatizada através de diversos meios acessíveis.

\footnotetext{
${ }^{3}$ Novas Tecnologias de Informação e Comunicação.
} 
Exigirá também do professor que saiba trabalhar em equipe, pois a apresentação final do seu trabalho envolverá várias pessoas: o professor irá selecionar o conteúdo e preparar seus programas de ensino; o editor dará legibilidade neste trabalho e o tecnólogo educacional organizará pedagogicamente os materiais. Para finalizar o artista gráfico trabalhará sobre a aparência visual e arte final do texto. Muitas pessoas da área de TI serão envolvidas neste processo.

Neste processo de aprendizagem aberta e autônoma, onde tantas tecnologias são incorporadas no novo processo de ensino, está à explicação da mudança do papel do professor: aqui o mesmo se tornará parceiro dos estudantes no processo de construção do conhecimento, em atividades de pesquisa e na busca da inovação pedagógica e fará com que o professor crie novos métodos para o trabalho docente com práticas inovadoras. Para que o professor passe da condição de "mestre" para posição de parceiro, este terá necessidade mais acentuada de atualização constante, tanto em sua disciplina específica, quanto em relação às metodologias de ensino e novas tecnologias. Além disso, ao invés de deter a palavra na sala de aula, passará para os diálogos dinâmicos dos laboratórios, salas de meios, e-mails, telefone, etc.

Analisando ainda o papel do professor universitário na EaD, listaremos abaixo algumas funções do professor presencial e algumas novas funções para o professor de $\mathrm{EaD}$ :

- Professor formador: orienta o estudo e aprendizagem, dando apoio psicossocial ao estudante, ensina a pesquisar, a processar a informação e a aprender; corresponde à função propriamente pedagógica do professor no ensino presencial;

- Professor conceptor e realizador de cursos e materiais: prepara os planos de estudos, os currículos e programas; seleciona conteúdos, elabora textos de base para unidades de cursos (disciplinas - componentes curriculares); corresponde à função didática, isto é, à transmissão do conhecimento realizada em sala de aula, geralmente através de aulas magistrais, pelo professor do ensino presencial;

- Professor pesquisador: pesquisa e se atualiza em sua disciplina específica, em teorias e metodologias de ensino - aprendizagem reflete, sobre sua prática pedagógica e orienta e participa da pesquisa de seus alunos; 
- Professor tutor: orienta o aluno em seus estudos relativo à disciplina pela qual é responsável, esclarece dúvidas e explica questões relativas aos conteúdos da disciplina; em geral participa das atividades de avaliação;

- Tecnólogo educacional ${ }^{4}$ : é responsável pela organização pedagógica dos conteúdos e por sua adequação aos suportes técnicos a serem utilizados na produção dos materiais; sua função é assegurar a qualidade pedagógica e comunicacional dos materiais de curso, e sua tarefa mais difícil é assegurar a integração das equipes pedagógicas e técnicas;

- Professor recurso ${ }^{5}$ : assegura uma espécie de balcão de respostas a dúvidas pontuais dos estudantes com relação aos conteúdos de uma disciplina ou questões relativas à organização dos estudos ou às avaliações;

- Monitor: muito importante em certos tipos específicos de EaD, especialmente em ações de educação popular com atividades presenciais e exploração de materiais em grupos de estudo ("recepção organizada"). O monitor coordena e orienta esta exploração. Sua função se relaciona menos com o conhecimento dos conteúdos e mais com sua capacidade de liderança, sendo em geral uma pessoa da comunidade, formada para esta função, de caráter mais social que pedagógico.

A metodologia abordada nesse artigo será a pesquisa bibliográfica, conforme Antonio Carlos $\mathrm{Gil}^{6}$ que define a pesquisa bibliográfica como aquela que utiliza como fonte, estudos científicos publicados em livros, impressos diversos e publicações periódicas como os jornais e as revistas, a:

"principal vantagem da pesquisa bibliográfica reside no fato de permitir ao investigador a cobertura de soma de fenômenos muito mais ampla do que aquela que poderia pesquisar diretamente”.

\footnotetext{
${ }^{4}$ Designer ou pedagogo especialista em novas tecnologias, a função é nova, o que explica a dificuldade terminológica.

${ }^{5}$ Muito solicitadas na época que precede às avaliações, esta função é normalmente exercida pelo tutor, mas não necessariamente.

${ }^{6}$ GIL, Antonio Carlos. Como elaborar projeto de pesquisa. 4aㅡ ed. São Paulo: Atlas, 2002: 44.
} 
A pesquisa bibliográfica também pode ser considerada como aquela que permite uma maior redução de custos, devido os dados pesquisados estarem disponíveis para futuras pesquisas, também possibilita a coleta de dados históricos só possíveis através da pesquisa bibliográfica.

Gil (2002), alerta para a desvantagem da pesquisa bibliográfica quando esta pode levar ao erro, se for realizada através de fontes secundárias que apresentam dados equivocados. Para corrigir esta possível falha, este projeto visa coletar dados de publicações certificas de autores e entidades reconhecidas no meio cientifico.

Os estudos de autores citados nas seções anteriores remetem á análise de que se as características e estruturas no ensino estão mudando, as funções do professor também sofrerão transformações. O professor não é mais a fonte principal do conhecimento, mas alguém que estimula, orienta o estudante na pesquisa de novos conhecimentos, lidando com os pós e os contras da tecnologia. Para este foco deverá estar voltado a formação de docentes do ensino superior para a EaD. Conquistar a confiança do professor nas inovações tecnológicas, gerenciar trabalhos em equipe, delegar tarefas e atualização constante, são temas que devem ser difundidos na formação desses novos professores. 


\section{Referências Bibliográficas}

BELLONI, Maria Luiza. Educação á distância. 3. Ed. Campinas. SP: Autores Associados, 2003.

GIl, Antonio Carlos. Como elaborar projeto de pesquisa. $4^{a}$ ed. São Paulo: Atlas, 2002: 44 .

LITWIN, Edith. Educação à Distância - Temas para o debate de uma nova agenda educativa. Porto Alegre: Artmed Editora, 2001.

MORAN, José Manuel. O que é educação à distância. Disponível em www.eca.usp.brlproflmoran ltextosead.htm

. Professores e gestores previsíveis e os inovadores.

Disponível em www.eca.usp.br\proflmoran\previsiveis.htm

PALLOF, Rena M; PRATT, Keith. Construindo comunidades de aprendizagem no ciberespaço. Porto Alegre: Artmed, 2002.

SEVERINO, Antônio Joaquim. Metodologia do trabalho científico. 21. Ed. São Paulo: Cortez 2000.

VOIGHT,Patrícia da Cunha Garcia. Investigandoo papel do professor em cursos de educação á distância. Disponível em www.abed.org.brlcongresso2004 \por\htm\143-TC-D2.htm. 